\title{
Online Language Teaching: the Pedagogical Challenges
}

\author{
Susan Yue Hua Sun* \\ School of Languages \\ Auckland University of Technology, New Zealand \\ E-mail: susan.sun@ aut.ac.nz
}

*Corresponding author

\begin{abstract}
Reflecting on the experience of teaching two fully online papers in Chinese at the Bachelor of Arts (Chinese) program at Auckland University of Technology (AUT) (delivered for a total of ten times since 2008), the object of this paper is to examine the problems along the way, and to address issues which arise. The problems are all pedagogical by nature, instead of being technical concerns upon which a large proportion of online language teaching research has been focused. The issues at stake are two very important assumptions: that there exists a Virtual Classroom, and that one can move the class to the cyberspace and build an Online Learning Community in online language teaching. Discussions are centred on the changing learner profile and the changed learner behaviours in online learning, and their far-reaching impacts on the way we traditionally teach. This author argues that both assumptions are mere myths, and urges a re-think of the online pedagogical approaches which still treat online courses as "classes" and insist on building the online learning community to re-invent traditional classroom-learning in cyberspace. An urgent call is then made for a radical pedagogical shift in online language teaching from teacher-centred approaches towards a personalised, small-group orientated, multi-dimensional model of teaching. In this spirits, a proposal on online language teaching design is formulated with specific and practical suggestions for online language teachers.
\end{abstract}

Keywords: Online Language Teaching Pedagogy; Online Teaching Approaches and Skills; Online Language Teaching Design; Virtual Classroom; Online Learning Community

Biographical notes: Susan Yue Hua Sun is currently a senior lecturer at the School of Languages in Auckland University of Technology, New Zealand. She earned her MA in Language Learning and Teaching from the University of Auckland, New Zealand, specializing in second/foreign language teaching. Her research interests include online language pedagogy, second language acquisition, CALL, learner autonomy and language education policy.

\section{Introduction}

Practitioners in the field of online language teaching have long recognised the differences between teaching in a traditional classroom and online, and the need for new teaching approaches and teaching skills (see for example, Barker, 2002; Bennett \& Marsh, 2002; Compton, 2009; Davis \& Rose, 2007; Hampel \& Stickler, 2005; Wilson \& Stacey, 2004). The myth that a teacher who is good at teaching in a face-to-face class can easily jump in and teach online (Davis \& Rose, 2007) is no longer entertained. However, exactly how 
different, and what the differences entail, is less clear. There seems to be little concerted effort in identifying and studying the new approaches and skills which online language teachers desperately need; and consequently, teacher training or professional development seldom goes beyond the technical and software-specific skills (Compton, 2009).

One of the first comprehensive studies which attempt to address the pedagogical aspects of online language teaching is by Hampel and Stickler (2005). On the basis of several years' experience in teaching languages online and training online tutors, they identify seven key competences necessary for successful online language teaching and present them in a pyramid (see Figure 1).

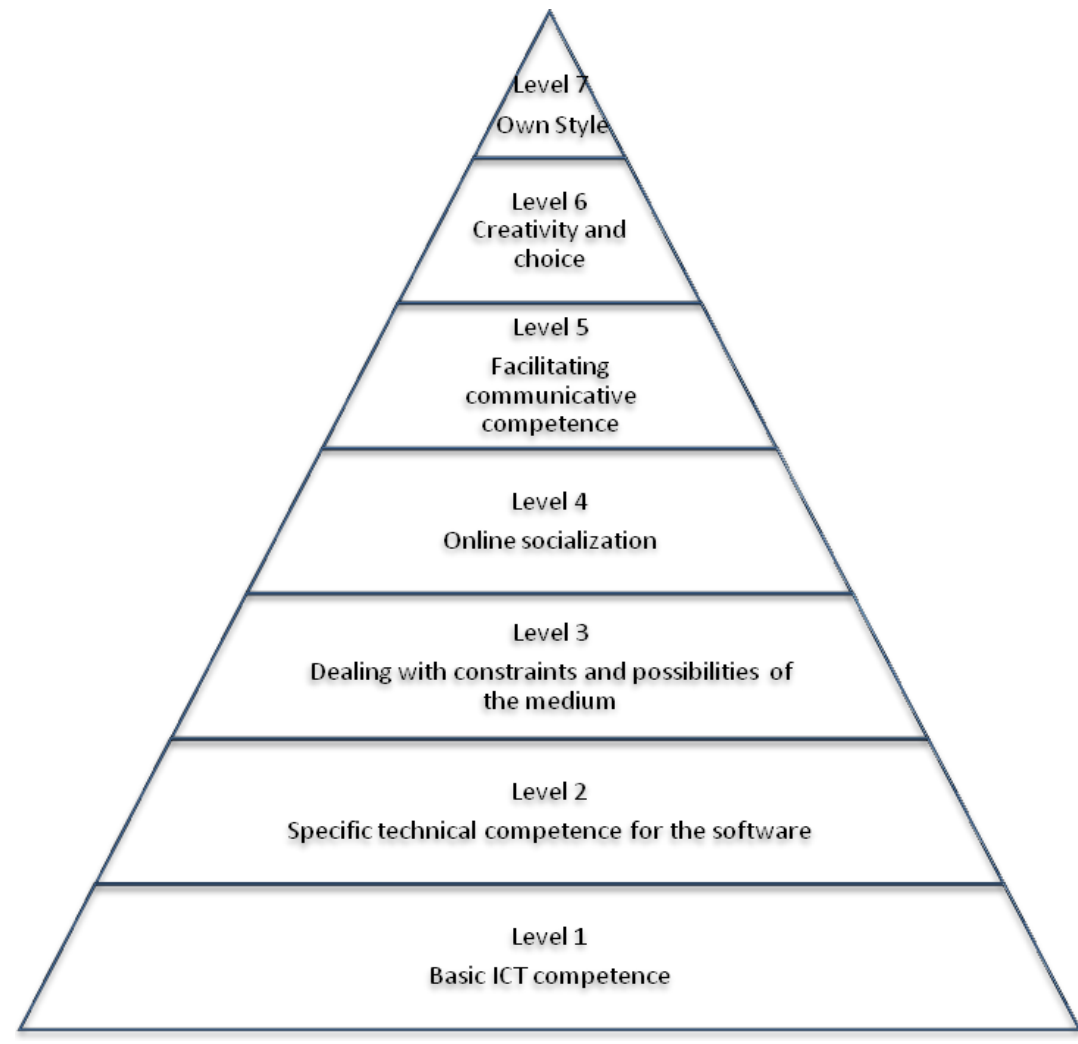

Figure 1. Skill pyramid (Hampel \& Stickler, 2005, p. 317)

In their framework, the basic competences (the three lower levels of the pyramid) are issues to do with hardware and software (Compton, 2009). Only level four and five seem to relate to teaching pedagogy. At level four - online socialization - they explain that "... socialization and community building in an online environment takes different skills than for the face-to-face classroom, there is no guarantee that even the most jovial and well-liked tutor of face-to-face course can become a successful online teacher at this level." (p. 318). At level five - facilitating communicative competence - they reiterate the value of "task design" and "tutor intervention" and see that as the ways to achieve "online interaction". However, advice like that proves to be vague and general, lacking in detail for teachers. 
Frustrated by the fact that "to date, no literature review has been published specifically on the skills needed for online language teaching", Compton $(2009$, p. 74$)$ synthesises the then "existing but limited literature" (p. 74) and proposes a pedagogical framework on online language teaching skills. In Compton's proposal (see Compton, 2009 , p. 82, Figure 2), the skills consist of three major areas:

1. Technology in online language teaching

2. Pedagogy of online language teaching

3. Evaluation of online language teaching.

Each of these areas are further broken down into three levels of expertise: novice, proficient and expert:

1. Technology in online language teaching

a) Skills for novice teacher

b) Skills for proficient teacher

c) Skills for expert teachers

2. Pedagogy of online language teaching
a) Skills for novice teacher
b) Skills for proficient teacher
c) Skills for expert teachers

3. Evaluation of online language teaching.
a) Skills for novice teacher
b) Skills for proficient teacher
c) Skills for expert teachers

Pedagogically (the second major area), Compton asserts that a novice online language teacher must learn and possess the knowledge of:

1. Strategies for online community building and socialising

2. Strategies to facilitate communicative competence and online interaction

3. Language learning theories for online language learning.

4. Curriculum design frameworks for online language learning

5. Strategies for online language assessment have the

As for the expert online language teachers, Compton believes that they should

1. Creativity in using and adopting materials to create new online language materials and tasks to facilitate communicative competence and online interaction

2. Creativity in facilitating online socialization and community building

3. Intuitive and integrated assessment of language learning.

These kinds of superficial talks, while it may be theoretically sound, practically it offers little help to the struggling online teachers. Compton does a fine job in summing up the areas, special skills and strategies which online teachers need to have, but falls 
short in providing much needed details for action. She mentions strategies for online community building, to facilitate online interaction, online language assessment, and the need for new theories specifically for online language learning, etc., but is unable to clearly spell them out in details. Just what exactly are these strategies and theories? What to do and how to do it? Furthermore, what are the "not to do" in online language teaching? What is most needed by online teachers is advice and guidance with sound theoretical basis for everyday teaching practice, but they are largely missing from the research literature. It seems that online teachers are, by and large, left to do their own experiments and perhaps learn from their own mistakes.

Despite the pedagogical frameworks by both Hampel and Stickler; and Compton are results of rather extensive research in the field of online language teaching over many years, and their literature reviews are meticulous and substantial, what they have painstakingly drawn up for online teachers is, nevertheless, very much lacking in details. A frustrated overnight-classroom-turned-online-teacher could find very few practical guidelines or immediate help in their proposals. The answers as to what to do and how to do it, or what not to do are still anyone's guess.

While Hampel, Stickler, Compton and others work on the broad, overall pedagogical frameworks for online teaching, many other scholars look at specific areas in online teaching. Guichon (2009), in an attempt to provide a theoretical framework for the organisation of online teacher training programmes, hypothesizes three competencies which language tutors need to develop in order to manage synchronous online teaching:

1. Competency of socio-affective regulation

2. Competency of pedagogical regulation

3. Competency of multimedia regulation.

Guichon defines competence of pedagogical regulation as: "first, the capacity to design learning scenarios adapted to distance that truly engage learners emotionally and cognitively and, second, to manage learning experiences by providing feedback tailored to learners' individual needs" (p. 170). This is again nothing new to online language teachers. What the experts are telling them seldom seems to match the real problems or issues which they encounter in their everyday teaching.

Synchronous online teaching in a virtual classroom is problematic from the outset. The reality is, gathering the class together online at the same time is getting harder and harder, let alone being able to present formal lectures and facilitate learning activities. Time zones, Internet connectivity and bandwidth, technical breakdowns, individual students' schedules (work vs. study), etc. are all real issues facing online teachers and learners. Even if a teacher manages to have students all coming to the virtual classroom at the same time, simple things such as the loss of lip synchronization and verbal clues, time lags, poor sound and images, turn-taking, etc. become huge challenges (Coverdale-Jones, 2000; Hampel \& Stickler, 2005; Wang, 2004). The solution offered by researchers for such problems and challenges are mostly and typically "techno training" for both teachers and learners and both before and during the course (see for example, Kabata \& Wiebe, 2005; Stickler \& Hauck, 2006a; Winke, Goertker, \& Amuzie, 2010). Many researchers earnestly believe the digital-age students would endure, through proper training, the feeling of uncertainty and anxiety, put up with the uncomfortableness, waste their time, and remain coming to the virtual classroom. Research into learners' perceptions of synchrony within the virtual classroom needs to be carried out, but existing literature does not focus on that (Parker \& Martin, 2010). It is simplistic to attribute the problems 
surrounding virtual classroom to purely technical ones. Some hard questions need to be asked, for instance, what are learners' perceptions of the virtual classroom, how does this initially technical issue impact on learning behaviour, and furthermore, how may changes of learning behaviour, if there is any, inform and help shape pedagogy for online teaching?

It is, therefore, the intention of this author to bridge, in the following sections, the gap between online teaching theory and practice by sharing with you the problems we encountered in delivering the two fully online papers and the challenges posed to both the teachers and students. The intension is to identify and explore new skills and approaches for online language teaching with learners firmly in mind. There will firstly be a presentation of the two major problems plugged persistently throughout the delivery of the two above-mentioned online papers. A discussion will then follow, in which learners' changing profile and changed learning behaviours are analysed, and the pedagogical implications are highlighted with an urgent call for learner-centred pedagogies to be adopted in online language teaching. Finally, a learner-centred online language teaching design is formulated and proposed to the online language teachers as a starting point.

\section{The Experience of Teaching Chinese Language Fully Online at AUT}

\subsection{The Context}

The virtual learning environment (VLE) at AUT is Blackboard in which the two fully online papers under discussion reside. Both papers are semester-long (15 weeks: 12-week teaching and 3 weeks for revision and final exams). They are the alternatives (fully online as oppose to face-to-face) to the first two papers in the Bachelor of Arts (Chinese) program, which have always been campus-based. The fully online papers are run alongside the campus-based ones ever since their launches: Introduction to Chinese I in semester one 2008, and Introduction to Chinese II in semester one 2009. They immediately attracted a large number of students from both inside and outside of the university. It is particularly popular among students in various bachelor degree programs in the university who take up Chinese as elective, minor or single major. The flexibility in time and space allowed in online learning seems to fit in well with these students' major study (or other major in the case of double major students). The two papers have now been delivered for a total of ten times since 2008 .

\subsection{The Delivery}

When given the task of designing and developing an online paper, the primary concern for the online teachers is usually: how do we transfer the traditional classroom to cyberspace? Guided by their professional expertise - competence in the language and culture, pedagogical knowledge and skills, and experience in teaching the language - the teachers decide that the first and last task would be to transfer whatever that have worked in a classroom to the cyber world. They are often led to believe that once the traditional classroom has been moved to the cyber world, technologies will somehow do the trick and take care of everything. The focus is therefore on the things that usually happen in a traditional classroom.

Our first task was to move the textbooks online using PowerPoint with pictures, sounds, culture and grammar notes, etc. embedded (see Table 1 which lists all the teaching components, and the methods and tools employed in these two online papers). 
Audio and video materials were then made or found through the Internet (e.g., YouTube) as learning materials or for tasks and activities. Electronic flashcards were made and they continued to be popular (they had been much loved by students in earlier blended learning).

Various kinds of online exercise for each lesson were created using Blackboard test and assignment tools. Online exercise questions are extremely time-consuming to make but very sophisticated and user-friendly. Not only are they asynchronous, which allow students to access them at anytime and anywhere, but they also offer features such as multiple attempts, automatic saving (students can stop and resume anytime), automatic correcting and scoring, questions-randomization, teacher feedback for individual or group, etc. The types of questions from which teachers can choose are extensive too: Fill in Blanks, Matching, Multiple Choice, Ordering, Short Answer, True/False, Essay, File Response, just to name a few. Furthermore, images, files (text/audio/video) and external links can be easily attached to the questions by the teachers or the answers by students.

Table 1. Summary of the Methods and Tools Employed

\begin{tabular}{|c|c|c|}
\hline \multicolumn{2}{|c|}{ Teaching Components } & Methods / Tools \\
\hline \multicolumn{2}{|l|}{ Lessons } & PowerPoint \\
\hline \multicolumn{2}{|c|}{ Lessons in Audio \& Video } & $\begin{array}{l}\text { Recording \& Filming } \\
\text { Sources from YouTube }\end{array}$ \\
\hline \multicolumn{2}{|c|}{ Electronic Flashcards (new words and phrases) } & AUT Package \\
\hline \multicolumn{2}{|c|}{ Online Interactive Exercises } & Blackboard Test/Assignment \\
\hline \multicolumn{2}{|c|}{ Individual Voice Recorder } & Wimba Voice Board \\
\hline \multicolumn{2}{|c|}{ Character-writing Movie Clips } & Adobe Captivate (software) \\
\hline \multirow{8}{*}{$\begin{array}{l}\text { Online } \\
\text { Community }\end{array}$} & Mini Lectures & Elluminate Virtual Classroom \\
\hline & Virtual Drop-in & Elluminate Virtual Classroom \\
\hline & Class Blog & Blog \\
\hline & Individual Blogs & $\mathrm{Blog}$ \\
\hline & Email/Voicemail Centre & $\begin{array}{l}\text { Email } \\
\text { Voicemail }\end{array}$ \\
\hline & Pair/Group Work Corner & $\begin{array}{l}\text { Elluminate / Wimba Voice } \\
\text { Direct Conference / Wikis }\end{array}$ \\
\hline & $\begin{array}{l}\text { Studio - for recording } \\
\text { Paired/Group Oral Presentations }\end{array}$ & $\begin{array}{l}\text { Wimba Voice Direct } \\
\text { Conference }\end{array}$ \\
\hline & Class Podcast & Wimba Podcast \\
\hline \multicolumn{2}{|c|}{ Assessment (assignments/oral presentations) } & $\begin{array}{l}\text { Blackboard Test/Assignment } \\
\text { Tools /Wimba Voice Tools / } \\
\text { Elluminate / Wikis }\end{array}$ \\
\hline
\end{tabular}

However, when it comes to submitting oral work, students do not need to make and upload audio files to the online questions. Online voice tools inside Blackboard make tasks like these much easier and simpler. A voice recorder (Wimba Voice Board) was set up for each student for recording oral work. Weekly voice recording tasks were assigned to students. All they need to do is to "click" into the recorder and start recording, then another "click" to submit the work. Teachers receive their work simultaneously, and can start giving feedback in text-mail or voicemail on the same page. Students love it because it is hassle-free - they can record and submit oral work in a matter of minutes and with just a few clicks. What's more, all their work, plus the teacher's comments, is kept inside the recorder like an eLibrary, and they can refer back later with just another click. This 
online voice tool proves to be most effective in developing students' oral abilities, especially at the lower-level classes.

Interestingly, students exhibit a very relaxed attitude and easiness towards using the voice recorder. They seem to like it and use the device a lot. The reasons could be that it is very personal, individual, and private: just between the student and the teacher without the gaze of fellow students. They practise speaking the target language and receive individual feedback from the teachers on every detail, which is very important for a beginner of a foreign language.

When it comes to teaching character-writing, we provide not only pictures of how characters are written (as shown below), but also make movie clips which capture the movements of the writing of characters stroke-by-stroke:

$$
\text { I 、占占, 占点点 }
$$

To our disappointment, many students at the end showed poor ability in recognising and writing characters. Compared with the on-campus students who did the same papers, online students' overall character reading and writing abilities were lower, which was somehow expected. How could a few movies of character-writing alone replace the constant writing of characters on the blackboard in a traditional classroom? On reflection, it seems that we indeed have taken the traditional classroom for granted. In the traditional classroom, character writing is not confined to scheduled sessions, as it is online. Rather, students have the benefit of observing how characters are written on the "blackboard" stroke-by-stroke on a daily basis. To alleviate the problem, we added character-writing tasks to students' weekly virtual drop-in, and added that to the class meetings as well, both of which happen in the Virtual Classroom (Elluminate) which will be introduced immediately below.

The disappearance of the actual classroom in online teaching is thought to be amendable by replacing it with a virtual classroom - synchronous real-time interaction and collaboration via desktop videoconferencing. A virtual classroom was then set up using Elluminate, where synchronous communication - text-chat and audio/video conferencing - could take place. There is an interactive whiteboard on which students can watch teachers writing characters, and in turn, show how they themselves would write them. Other functionalities include document-sharing, Internet-surfing, breakout rooms, etc. It was all very exciting that a virtual classroom seemed to be able to do everything a class needs. Teachers started, rather eagerly, to plan some mini lectures of 20-30 minutes which included 10-minute lecture and 10-minute group tasks/activities. Mini lectures were to be conducted once every one or two weeks. Regrettable, it didn't eventuate as planned. We shall discuss this in more detail in Section 2.3 below.

The Elluminate was also used to host the one-hour weekly Virtual Drop-in. Students are encouraged to drop in causally any time during the hour where they could ask questions they might have, oral-practice and write characters, or simply have a chat with the teacher. This design took off smoothly and went unexpectedly beyond its original aims. Detailed discussion on this will also be presented in Section 2.3 below.

The next thing to do in our design was to build an online learning community. Trying to re-invent the kind of "community" where online students can meet, study together and hang out, we firstly set up a Class Blog, a most convenient platform for socialising and organising pair/group work. A ready-to-go email/voice-mail centre, where 
teachers and students can email or voicemail anyone in the class, was also set up: just click the name, and start writing or speaking.

Inside the community, there is also a Pair/Group Work Corner. Students are required to pair or team up and have oral or writing practice sessions there on a weekly basis. They may choose to practice speaking in their own way, or follow the worksheets provided. Every few weeks, each pair/group is required to produce an Oral Presentation, like a play. The tools used for that are Wimba Voice Direct Conference or Elluminate. Students tended to choose Elluminate more because Wimba Voice Direct Conference, while it is available exclusively for the class at all time (24/7), it doesn't allow people talking simultaneously (one talker at a time). Students have to wait for their turn to speak. While students favour the Elluminate where it is synchronous and they can work with their peers in all formats (text/audio/video), the downside is that it's used by many other AUT online classes. They sometimes found themselves entering into a pre-booked session like the Mini Lecture and the Virtual Drop-in mentioned earlier. Gradually, they learn to meet up their peers in the evenings or weekends at the Elluminate to avoid prebook classes. Another downside of using the Elluminate for pair/group work is that not all the functions are operational when there is no teacher (moderator) present, e.g., fileimporting and file-sharing.

To do the paired/group oral presentation, students would firstly work on a wiki page, drafting and editing together; then practice (role-play) the presentation. After much practice, they would go to a "studio" (Wimba Voice Direct Conference) to record their presentation.

A Class Podcast was also set up inside the Online Learning Community. Students were encouraged to record or upload audio/video clips of their speaking Chinese and share with the class every now and then.

Assessment consisted of assignments and individual or paired/group oral presentations are carried out completely online using the Blackboard test tools, Wimba voice tools, wiki and Elluminate (see Table 1 for a summary of all the methods and tools employed in delivering these two online papers).

Technology displays its spectacular power inside this online learning community everything needed for communication, interaction and collaboration is there! Everyone in the class is truly just one-click away! We anticipated a lot of traffic inside the community. The beauty is that, while learning and communicating, everyone has the luxury of sitting in front of his or her own computer in their chosen timeframe.

With all these setups inside the Online Learning Community, one could almost see it bursting with activity - a lot of coming and going, and a lot of interaction. That is exactly the intention of the teachers: to re-invent the interactive environment which traditional language classrooms inherently have, where students have virtually no chance to play with the target language alone. Language teachers know well through their own second language learning and teaching experiences that communicative language can only be learnt in a community. However, despite all the efforts bringing in the latest online communication technologies available, we found it extremely difficult to bring in the supposedly hectic interactions amongst students. We will return to the topic of online learning community with detailed discussion in section 2.4 below.

Pedagogically, while the design of the online papers was under heavy influence of the traditional teacher-centred teaching approach, some of the teaching components and the methods used also exhibit a fair amount of elements of the constructivists' theory, e.g., the Class Blog, the Pair/Group Work Corner (Elluminate), and the Paired/Group Oral 
Presentations. Constructivist theory has been increasingly influential in education in recent years, especially in higher education. Central to the constructivist's theory is the shift of the role of the teachers and learners: teachers become instructors or facilitators and "the learner moves from a passive role receiving an instructor delivered didactic lecture, to an active role where they participate in learning. The learner collaborates with both the instructor and other learners creating a dynamic interaction" (Johnson, Corazzini $\&$ Shaw, 2011, p. 6). The constructivist theory provided certain degree of imputes for the design of the class blog, pair/group work corner and paired/group oral presentations in the online papers. It was hoped that through socializing in the class blog and process of discussion and collaboration at the work group work corner, students could teaching one another and learning could be optimized.

Admittedly, we had very little idea as to whether the design was going to work. Below are the two major problems we uncounted.

\subsection{Virtual Classroom - Is it wishful thinking?}

One of the major problems plugged persistently throughout was the mini lectures we planned to hold at the Elluminate Virtual Classroom. Despite vigorous promotion of the virtual classroom lectures to the students right from the start, we nevertheless seldom managed to hold classes there. Only some students came to the lectures while many others could not or did not come at all. Some of those who came would very often spend long time just trying to $\log$ in. They would then spend a further 5-10 minutes dealing with technical problems related to their equipments (headset, sound level, video image, etc.) before finally settle down. These recurrent troubles must be driving students away because it seems many of the students simply do not come back again. Then there were always some students who couldn't hear or be heard, and someone's Internet was too slow or stopped randomly, let alone the choppy videos. When students answered questions by the teacher, it was awkward as social etiquette, rules of turn-taking, etc. had not yet been established among the group. It was supposed to give the process enough time for people to get to know one another better. However, before it happened, most people would already have shied away from the Virtual Classroom.

Our experience seems to indicate that traditional classroom cannot be easily replaced. You could schedule as many sessions in the virtual classroom as you wished, and organize interesting and stimulating learning tasks and activities around them. In reality, students do not seem to consider it as "classroom", and teachers in fact have little control over its being used or not, let alone have regular "classes" there.

Besides, how many online meetings in the virtual classroom, compulsory or voluntary, can a teacher schedule in a paper? To many students, online learning is a revolution, in that learners are finally "liberated" and left alone. The usual catch phrase regarding online study is: learn at the convenience of your own time, own place and own pace! As a result, online students quite often resent compulsory virtual classroom meetings that "give students flexibility in place, but not in time" (Parker \& Martin, 2010, p. 94). This may explain why only a few people attend the virtual classroom class meetings each time. For many, this so called "classroom" is no more than another "setting" or "folder" among other asynchronous features in the course, e.g., learning materials, blog, wiki, voice recorder, group emailing, etc. which they dictate when to "click the button".

Interestingly, students do come to the virtual classroom when it is not a scheduled class meeting. For instance, the weekly Virtual Drop-in at Elluminate proved to be very 
popular and frequented by individual students who are "dropping by" casually and looking for a one-to-one session with the teacher. There they read out, much more at ease, lessons, do character writing or role-play with the teacher, ask questions, or sometimes just have a chat! What is intriguing is sometimes when the teacher is working with one student at the virtual classroom and another one or two students drop by, the students would happily pair/team up and do some tasks together. It contrasts sharply with the reluctance they show in virtual classroom meetings (mini lectures) when we try to get them to talk to each other or work together in the breakout rooms. It is even more intriguing that when the number of drop-in students reaches four or five, some students would start making their way out, and sometimes return later. A group with two to four people seems to be the most comfortable size for student interaction in the virtual classroom. This confirms the finding by Brown and Adler (2008) that students working in small groups learn more than those who work on their own.

Under the circumstances, we were forced to abandon the online synchronous class meetings, i.e., mini lectures, and to find alternative ways to teach. It is apparent, from our experience, that the traditional classroom cannot simply be re-invented in online courses, and online language learning and teaching is indeed a completely new adventure. Online students do not go to a "room" and learn with a group like what it is in a traditional classroom, despite teachers' desperate insistence. The reasons behind that could be manifold. We shall explore this in the discussion section later.

\subsection{Online Learning Community - Do we know its shape and form?}

The second major problem we encountered was the building of a functioning online learning community. Although we present the first major problem (Virtual classroom) and the problem with the online community in separate sections $(2.3 \& 2.4)$, the two are not entirely separate issues. Rather, they are interrelated in many ways.

Traditional language classrooms are interactive by nature, in that students have virtually no chance to play with the target language alone. While teachers routinely plot, prompt, and facilitate a lot of interaction, a lot more interactions happen spontaneously. As for socialisation, there is nothing much that the teachers need to do. They usually sit back and watch the students doing the socialising.

Disappointingly, sometimes for days or even weeks, our Online Learning Community was very quiet, and people used it for what we called "minimal and survival" communication and interaction only. Despite having various platforms for interaction, people seemed to be unaffected, preferring sitting back at home doing the good old selfstudy or working quietly in pairs or small groups behind the scene. They did wonderful work on their own and made good progress, but were seldom visible in the community. The constant interaction amongst students in a traditional classroom, social or studyrelated, was not seen here.

The online learning community was set up in an attempt to, at the very least, introduce everyone to everyone. Once they all know each other, they would start bonding, we expect, just like in the face-to-face classroom. With careful and skilful facilitation by the teachers, everyone would come on board, socialize, interact and collaborate, we believed. It proves, however, to be only wishful thinking on our part. Nevertheless, students do try. At the first few weeks, students would usually do a lot of greeting the class: writing in the class blog, posting messages addressing the whole class, using group emails, trying pairing up or grouping, organizing practice sessions and so on. However, it would soon become quiet in the third or forth weeks when most of them would have 
paired up or teamed up. They would start disappearing from the community. Activities inside the community would become much less frequent, and the activities become more personal and one-dimensional: one student to or with another student. People are no longer interested in communicating with the class. Instead, they only talk to their pair/group members. They explain that they don't have the time to socialise with the whole class. No one in the class seems to mind, either.

It seems that the good old traditional classroom proved to be more than just a room where people meet and learn. It was grossly ignorant and uninformed on our part to think that by re-inventing its formats or settings through smart modern technologies, traditional classrooms could then be moved or replaced. It becomes clear to us that an online community can be built through technology, but a truly functioning online learning community is much harder to come by. That was another setback we had in the effort of trying to pull an online learning community together.

Efforts immediately went into building and fostering a functioning community, e.g., the learning exercise/activities were re-designed to be more task-based, interactive and real-life problem-solving, and the assessment was closely examined to include more pair/group collaborations. Although the online community became a bit busier upon those changes, it was still somewhat disappointing. Online interaction amongst students still seemed to be at the "necessity" level - if they had to do certain things to complete an assessment item, then they would do it. Compared with a traditional classroom's spontaneous interaction, online interaction seems superficial and rather feeble.

This is not to say that online language students do not develop their oral skills as well as the on-campus students. On the contrary, their speaking ability is, on average, as good as that of the on-campus students. After completing these two online papers, some of the students went on to do a higher-level paper where they met other students who had completed the same two papers delivered on campus. No marked difference in oral ability was noted between the two groups. We attributed this partly to the setup of individual voice recorders for each student, and partly to the quiet working of pairs and small groups behind the scene.

Our observation indicates that students like to meet in pairs or small groups (a maximum of four people). They at first relied on various online tools to communicate and work together, e.g. email, blog, Elluminate, wiki, etc., but once they've formed pair or group and got to know each other better, they often moved out of the online environment and met in more conventional ways, e.g., by telephone or face-to-face. Once again, it's easy to see, the relaxing attitude and easiness which they displayed when working in pairs or small groups. This contrasts starkly with the reluctance that they consistently showed towards attending class meetings in the virtual classroom. There is no doubt that online students do become involved within the online learning community. The question is only where, when, and how, and ultimately, how do we define an online learning community? What is its shape and form? Do all members of an online community ever meet together at the same time, let alone work together, in the virtual environment?

\section{Discussion}

Two breakdowns in online language teaching have been described, both concerning learner participation and interaction in online courses, one the unattainable virtual classroom class-meeting (lecture), the other the lack of interactions amongst members in the online learning community. 
Learner participation and interaction is in the central place and of crucial importance in successful language learning, whether it's face-to-face, blended or fully online teaching. This is because "language learning is a skill-based process rather than a content-based one. Skill developments, such as the acquisition of speaking and listening skills, required constant synchronous interaction in the target language" (Wang \& Chen, 2009 , p. 5). Language teachers firmly believe in that, knowing a large part of language learning takes place among peer interaction. This is why online teachers are easily persuaded and throw themselves enthusiastically into building online learning communities. It is for this same reason they try hard to organize and manage the virtual classroom in an attempt to foster real time synchronous interaction so that language learning could take place. Wang and Chen (2009) stress that synchronous oral and visual interaction is a crucial component in online language learning and fostering real-time synchronous interaction is an important principle in distance language teaching.

Current online learning management system (LMS) (in our case, blackboard) is equipped with a lot of functionalities and tools which are asynchronous, e.g., learning material management, blog, wiki, discussion forum, group emailing, etc. They do not facilitate synchronous interaction. Teachers are acutely aware that the only place to facilitate synchronous interaction is the virtual classroom (in our case, Elluminate), where flexibility of place and, most importantly, synchronization of time become possible. That's why a lot of effort went into organizing classes in the virtual classroom. We deliberately placed the virtual classroom inside the Online Learning Community in an attempt to facilitate, as much as possible, "synchronous multi-way interaction" (p. 5) amongst class members. We insist that the virtual classroom must work.

Regrettably, in our case, it appears that it was foredoomed to fail. However, one should still appreciate online teachers' efforts and determination in replacing the traditional classroom with virtual classroom. This determination has also been, for a long time, encouraged vigorously and almost systematically by numerous studies, which explore the skills online teachers have to possess to teach effectively and focus heavily on the management of teaching a class or large group in a virtual classroom (see for example, Guichon 2009; Hampel \& Stickler, 2005). For instance, Guichon (2010) shares with us that both the temporal pressure exerted by synchronous communication and the technical failings of the videoconferencing platform (breakdowns, discrepancy between sound and image) make the teaching task more complex to carry out. He advises that teachers learn to coordinate their pedagogical action between the different means available to them (voice, facial expressions, gestures, images, text) and the different tools (webcam window, textual chat), and make appropriate and timely choices (p.174).

Unfortunately, the kind of technology-focused approach which insists that teachers must develop competence and skills in managing a virtual classroom has mislead teachers into believing that the loss of the traditional classroom can be made up by the virtual classroom, and they can continue to organize class lectures and design various group task/activities there. It seems all they need to do is to learn some new crafts in dealing with technical failings, e.g., breakdowns, choppy video, discrepancy between sound and images, which could generate a great deal of anxiety and exert temporal pressure (Guichon, 2009). We now know that this is untrue. Even if the traditional classroom could be re-constructed in cyberspace and functioned as well as the traditional one, several problems, which are beyond the control of the teachers, remain. Below is the three major issues needed to be addressed urgently. 


\subsection{Change of Learner Profiles}

Virtual classroom synchronous conferencing has a temporal dimension in that it requires simultaneous presence of the participants. The unique and core characteristic of the virtual classroom is the requirement for time-synchrony. However, tertiary student profiles are rapidly changing. "A large proportion of students now juggle work and study" (McLoughlin \& Lee, 2010, p. 31-32). This is especially true for online learners. While they enjoy tremendously the flexibility in both place and time which online courses offer, many of them simply cannot work with a fixed timeframe required by the virtual classroom. Our experience is: you can never find a day and time (weekdays? weekends? daytime? night-time?) which is suitable for everyone, thus you can never have a "class", even a brief one. It is therefore better to consider online language teaching as one-to-one, or at the very least small group teaching (see Figure 2).

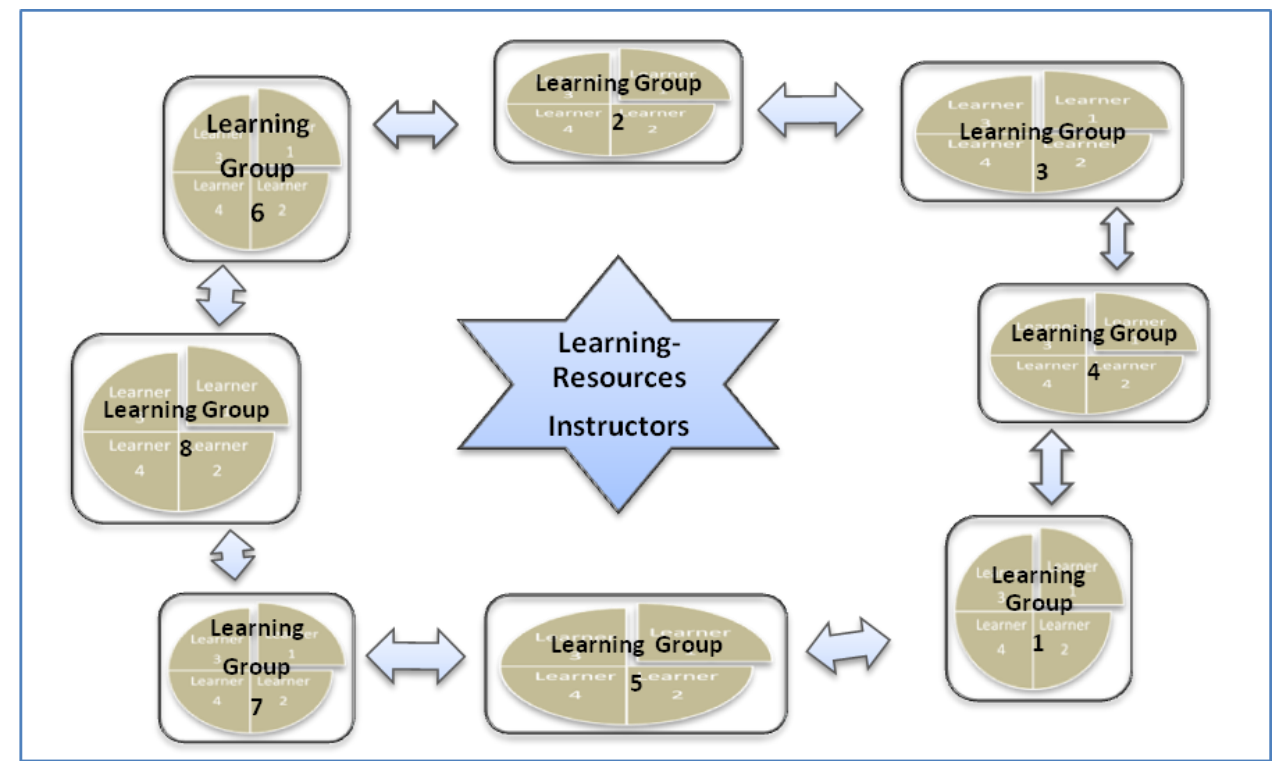

Figure 2. The Shape and Form of an Online Learning Community

The norm of online teaching seems to be that (a) teachers interact with students on a one-to-one basis and or sometimes with small groups (up to four people), (b) instructions and feedback on performance (sometimes learning materials and assessment) are individualised, and (c) students work within their own little group and seldom communicate and build meaningful relationships with class members in other groups.

It will better reflect the realities of the online learning environment if we consider an online class as a big wide network consisting of many nodes of small groups, which further break down into pairs and individuals. They cluster in this net like a rhizome, carefully scaffolding by the instructors/teachers using various online technologies. The entire network simultaneously holds multi-level interactions amongst its members: oneto-one, one-to-many, many-to-many.

Each learner forms a learning centre of his own (see Figure 3), and he has almost full control over when to attend the virtual classroom, when to meet his learning partners and group, when to access the learning materials, when and how to study, and so on. His timetable is personalised according to his work schedule and life-style. Time is lost in 
online community. Everyone is taught, studies, and works in his own manner and time frame.

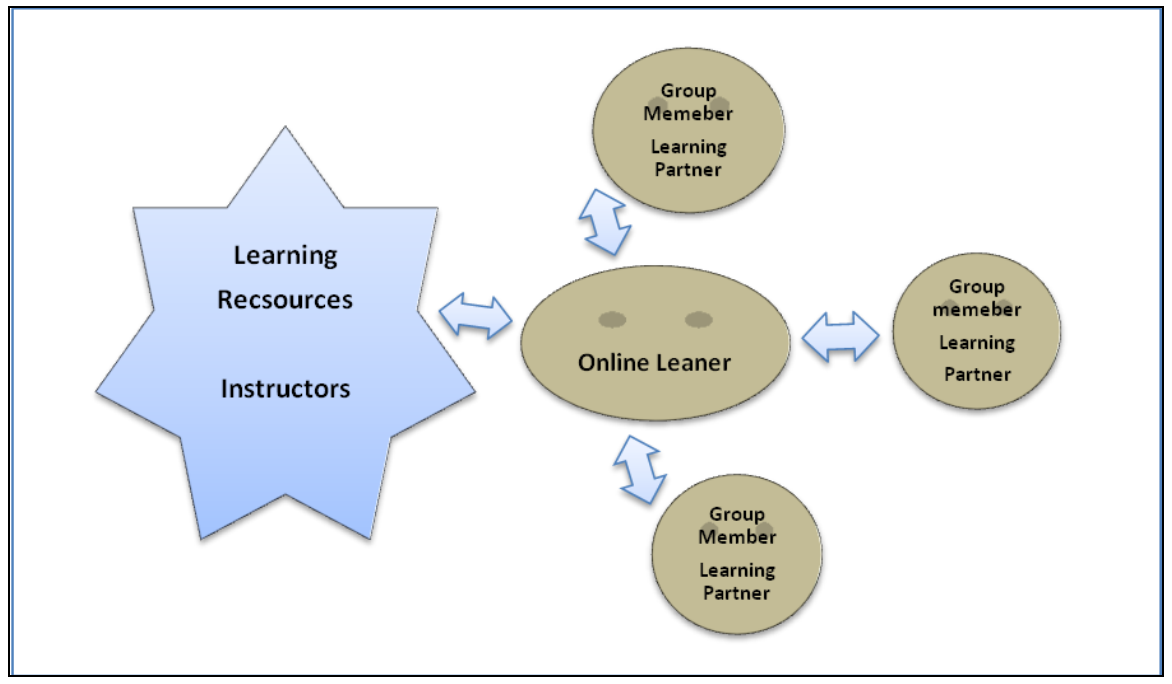

Figure 3. Online Learner's Learning Centre

\subsection{Change of Learning Behaviours}

New technologies, especially synchronous technologies such as virtual classroom audio/video conferencing, have certainly brought new challenges to online teachers. The difficulties and pressure experienced by online teachers in virtual classroom sessions have been widely reported and as a result many technical "how-to" guides (Hampel \& Stickler, 2005) have been offered to teachers. Many teachers adopted the new approaches and strategies, and changed the way they teach.

This kind of behavioural change prompted by new technologies also happens to online learners, though not many people realize it or are keen to know more about it. In consequence, the challenges and pressure new technologies pose for online learners have been less studied and little known, e.g., equipment (of the learners) failing, multiple overlapping of voices, turn-taking, pausing, negotiation to "regain the floor" (Jenks, 2009), lacking non-verbal clues, just to name a few. It was not uncommon, in our experience, that students logged in and out of the virtual classroom repeatedly just trying to get the sound and images right. It happened very often too that students were so frustrated during a virtual classroom session that they gave up trying and disappeared.

Technical failing and its pressure on the learners are real, and should not be overlooked. Its impact on online learners' learning behaviour is far-reaching, and beyond the compass of technology in our case. The way the virtual classroom operates has scared away, literarily, many students. They have not only shied away from class meetings at the virtual classroom, but also subtly altered the ways they interact with teachers and fellow students. When class or large group activities become unmanageable in the virtual classroom, students would adjust their learning styles by forming smaller group or working in pairs. They prefer small group collaboration in online learning environment. With the class "falling apart" and students stopping trying to know and work with other members of the class rather than their own small group, the online learning community 
seems almost non-existing. What we witness here is learners adopt a more personal approach in learning. Along with learning environment changes, people's learning methods and styles also change.

Researchers have long argued that in online learning communities, social interaction and bonding, that is, the forging of intimate friendships, is fundamentally different from in real-life situations. Online communication is superficial and requires time to mature (Harrison \& Thomas, 2009). With the absence of a real-life classroom, which is the most familiar form of communication which students have known all their lives, and where they have been able to interact naturally and regularly, they indeed are entering unknown territory in online learning. There is inherent anxiety and uncertainty caused by online technologies. It is almost impossible to face-read and lip-read, and to observe body language in a virtual classroom. Images and sounds are distorted, and people's movements are restricted. It takes a much longer time to get to know someone in the class and to develop a relationship under the circumstances. All of which should help explain why online students give up being part of the class at a very early stage. Instead, they invest their time and effort into building and maintaining pair or small group relationships, which are much more manageable and effective.

Harrison and Thomas (2009) report similar findings when they examined an online community Livemocha, which was specifically aimed at encouraging collaboration between foreign language learners. They found that, when presented with various learning tools, learners "actively choose the tools they feel they need to achieve the goals they set for themselves, and create their own learning environment from the options available" (p. 120). Harrison and Thomas believe that what they were witnessing was a radical shift in the way people learn languages - independently through choosing their own tools, and, as a consequence, creating their own "Personal Learning Environments".

In this environment, a learner is not only able to decide their timetable (as we have discussed in Section 3.1), but also able to choose his own learning materials, partners and group. He chooses his own tools to best suit his learning methods and style. Nothing is, however, static. His learning environment continues to evolve as learning progresses. He is the centre and everything else, e.g., learning materials and tools, teachers and peers, etc., circle around him (refer back to Figure 3).

It is most important that we should remember that there are as many personal learning environments as there are members of the learning community in an online class. These personalised environments spread around the 'big wide net' of the online community, like a rhizome, and no single one behaves quite like another.

We finally have a clearer view of what an online learning community (online class) looks like (refer back to Figure 2 and Figure 3). Its shape and form is, arguably, the direct result of the changed behaviours of the online learners.

If students have changed their learning behaviours, i.e., avoiding coming to online classes at the virtual classroom and choosing other methods (tools) to study, isn't it time too to re-think the role, and perhaps the name as well, of the virtual classroom? It is about time too for online teachers to give up some of the time-honoured, ingrained classroom teaching approaches and methods. If online language learning is increasingly becoming small-group adventures, isn't it high time and in the best interest of online teachers to re-think the way we organize the online learning community? The emerging picture of the online learning community demands online teachers to change and adapt too, i.e., learn to be a one-to-one or small group tutor, personalize their contact with students, and so on. 
This leads to our discussion in the next section on the pedagogical implications for online language teaching in the light of the changed online learning behaviours.

\subsection{Rethinking Pedagogy}

Personalized learning is a phenomenon emerged in the twenty-first century globe learning landscape transformed and shaped by the digital communication tools and ubiquitous networked applications. It forms part of the pedagogical shift from the traditional teacher-centred teaching approach whereby learning content is composed, organized and packaged to a learner-driven, learner-centred teaching approach whereby students are able to choose and personalize what tools and content are available (McLoughlin \& Lee, 2010).

Learner-centred approach considers learners as the key agent of the learning process (White, 2003), and a defining element in online learning (Wang \& Chen, 2009). Learners are no longer passive recipients of formerly constructed linguistic knowledge from the instructor's perspective (Chambers, 2005). Furthermore, course design and delivery are driven by learners' interests and needs. Teacher must create diverse learning environments to enable personalized learning and allow learners to make decisions about how to choose tools and configure the learning environment to best suit their learning goals and needs (McLoughlin \& Lee, 2010).

What makes this emerging pedagogy significant and powerful is that learners, not teachers or educators or researchers, creates this extraordinary new way of learning, as we have witnessed in the two fully online papers under discussion. The two papers were developed and delivered predominately under the guidance of the traditional teachercentred pedagogy (at least in the early days). The learning materials, learning tasks and activities, group work, assessment - all of which resembles teaching in a teacher-driven environment and seldom goes beyond "automated learning resource delivery" (Palmer \& Holt, 2009). The teachers had so much confidence and faith in the ways they had always taught until the setbacks - problems with the virtual classroom and the online learning community. It was at that point, the students "exercise ownership and control over their experiences" (McLoughlin \& Lee, 2010, p. 30). They became the drivers of the course and used the technologies available to their advantage. They abandoned the virtual classroom class meetings (mini lectures), instead, formed small learning groups, and thrived. This is indeed a testimony to what White (2003) promotes that "learner as the key agent in the learning process". Teachers no longer knew and had little control over how those pairs and small groups interact and collaborate. Learning was de-centralised and became personalized. Even more compelling was the fact that personalized learning took root in the most improbable soil: a near-reduplication of the traditional teachercentred model, which did not set out to allow much input from students, and which must instead have constrained personalized learning. Yet, personalized learning broke out from this depressing learning environment and performed a great feat!

Teachers have little choice now but to re-think the traditional pedagogies which they have held dear for a long time, and to adopt new pedagogies, such as the constructivist student centred teaching approach.

The characteristic of constructivist learner-centred pedagogy in online learning setting has been widely discussed by many researchers in recent literature (see for example, Compton, 2009; Hampel and Stickler, 2005; Johnson, Corazzini \& Shaw, 2011; Lai, Zhao, \& Li, 2008; McLoughlin \& Lee, 2010; Wang \& Chen, 2009). Derived from their discussions, some defining elements emerge as follows: 
- Promote learner participation and engagement

- Facilitate multi-dimensional interactions

- Foster the building of learning community

- View learning as a process

- View group-work and project as important part of learning

- Encourage group discussion, initiatives

- Encourage learners to construct their own understanding, co-construct class resources and the learning environment, co-create new learning and knowledge

- Learn in small groups

- Favour task-based instruction

- Emphasise learner cooperation and collaboration

- Foster real-life problem-solving, critical thinking skills

- Assert learner-control

- Promote self-direct, self-regulated learning, individualized/personalised learning

- Encourage learner creativity

- Use authentic learning materials

Informed by both the research literature in learner-centred pedagogy and the observation of the way student learn in the two online papers under examination, we have gradually revamped the delivery of the papers, and are able to propose here, tentatively, a new design (see Table 2). The teaching components are the same as in the first design (refer to Table 1), but new methods and strategies are employed in this second design, inspired by the learner-centred pedagogy. Brief comments with regard to the learnercentred characteristics are made on each method or strategies employed. It's hope that the design could serve as a starting point for novice online language teachers when designing an online language course.

\section{Conclusion}

In this study, class (big group) meetings at Virtual Classroom is analysed and proven to be unattainable; and the shape and form of the online learning community is explored and emerged. Its spectacular new look resembles very little of the traditional classroom, and is in many ways unprecedented, e.g., the roles and relationships of the teacher and student, learning behaviours, learning patterns and styles, just to name a few.

It's fair to say that online learning has substantially changed the way people learn as we have reported here on the delivery of two fully online papers. While this study tries to shed light on how online learners undergo behavioural changes, the more pressing issues are, nonetheless, on how online teachers should teach, presented with a brand new educational landscape which has been and still is being transformed and shaped by ever sophisticated communication technologies. Traditional teacher-centred pedagogy has proven to be out-dated and a constraint to online learner. Online teachers must adopt new approaches with learners at heart.

Online language teaching and learning is dynamic and undergoing changes all the time, just like technologies do. It's crucial that online teachers constantly review and reflect on their practice and remain committed to change. The urgent need at present seems to be a radical shift of pedagogy towards an individualised, small group orientated, multi-dimensional model of teaching. 
Table 2. Proposed Learner-Centred Online Language Teaching Design

\begin{tabular}{|c|c|c|c|}
\hline \multicolumn{2}{|c|}{ Teaching Components } & New Strategies/Methods & Pedagogical Characteristics \\
\hline \multicolumn{2}{|c|}{ Lessons } & $\begin{array}{ll}\text { - } & \text { leave room for students to nominate } \\
\text { topic/subject areas of study } \\
\text { - } \\
\text { students find learning contents of } \\
\text { interest }\end{array}$ & $\begin{array}{ll}\text { - } & \text { learner co-construct class } \\
& \text { resources } \\
\text { - } & \text { assert learning control }\end{array}$ \\
\hline \multicolumn{2}{|c|}{$\begin{array}{l}\text { Lessons in Audio \& } \\
\text { Video }\end{array}$} & - $\quad$ stay & $\begin{array}{l}\text { - use authentic learning } \\
\text { materials }\end{array}$ \\
\hline \multicolumn{2}{|c|}{ Electronic Flashcards } & $\begin{array}{l}\text { - } \quad \text { provide software package for students } \\
\text { to work in groups to make flashcards } \\
\text { (record sounds, find pictures, etc.) }\end{array}$ & $\begin{array}{l}\text { - } \quad \text { roup work, cooperation \& } \\
\text { collaboration }\end{array}$ \\
\hline \multicolumn{2}{|c|}{$\begin{array}{l}\text { Online Interactive } \\
\text { Exercises }\end{array}$} & 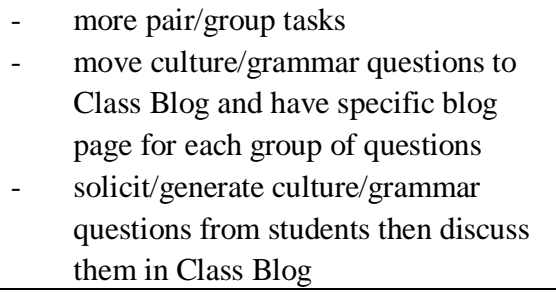 & $\begin{array}{ll}\text { - } & \text { encourage participation and } \\
\text { interactions } \\
\text { - } & \text { encourage learner } \\
\text { initiatives, creativity, } \\
\text { problem-solving } \\
\text { - } & \text { community building }\end{array}$ \\
\hline \multicolumn{2}{|c|}{$\begin{array}{l}\text { Individual Voice } \\
\text { Recorder }\end{array}$} & $\begin{array}{l}\text { - move some individual oral recordings } \\
\text { to Class Podcast }\end{array}$ & $\begin{array}{l}\text { - individuals share own } \\
\text { learning experience and } \\
\text { progress, help develop sense } \\
\text { of belonging in the } \\
\text { community }\end{array}$ \\
\hline \multicolumn{2}{|c|}{$\begin{array}{l}\text { Character-writing Movie } \\
\text { Clips }\end{array}$} & $\begin{array}{l}\text { - invite students to browse the Internet } \\
\text { (e.g., web dictionary: nciku) and find } \\
\text { more character -writing samples }\end{array}$ & $\begin{array}{l}\text { - } \quad \text { co-create new learning and } \\
\text { knowledge }\end{array}$ \\
\hline \multirow{8}{*}{ 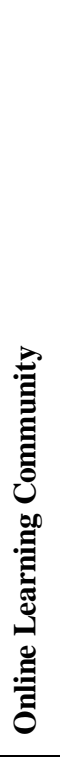 } & Mini Lectures & $\begin{array}{ll}\text { - } & \text { reduce to a minimum } \\
\text { - } & \text { pre-record the lectures and make it } \\
\text { available online }\end{array}$ & $\begin{array}{ll}- & \text { increase learner choice } \\
\text { - } & \text { promote personalised } \\
\text { learning }\end{array}$ \\
\hline & Virtual Drop-in & - $\quad$ stay & $\begin{array}{l}\text { - participation, engagement, } \\
\text { interaction }\end{array}$ \\
\hline & Class Blog & stay & community building \\
\hline & Individual Blogs & $\begin{array}{l}\text { stay, but encourage more postings on } \\
\text { target language and culture created or } \\
\text { found by individual students }\end{array}$ & $\begin{array}{ll}\text { - } & \text { socialising, community } \\
\text { building } \\
\text { - } & \text { learner creativity } \\
\end{array}$ \\
\hline & $\begin{array}{l}\text { Email/Voicemail } \\
\text { Centre }\end{array}$ & - $\quad$ stay & $\begin{array}{l}\text { - } \quad \text { socialising, community } \\
\text { building }\end{array}$ \\
\hline & $\begin{array}{l}\text { Pair/Group Work } \\
\text { Corner }\end{array}$ & $\begin{array}{l}\text { - stay, but consider adding Second Life } \\
\text { and bring in native speakers }\end{array}$ & $\begin{array}{l}\text { - authentic, real-life problem- } \\
\text { solving }\end{array}$ \\
\hline & $\begin{array}{l}\text { Studio - for } \\
\text { recording } \\
\text { Paired/Group Oral } \\
\text { Presentations } \\
\end{array}$ & $\begin{array}{l}\text { stay, but encourage other methods of } \\
\text { making oral presentations, e.g., } \\
\text { filming }\end{array}$ & $\begin{array}{ll}\text { - } & \text { task-based, group work } \\
\text { - } & \text { learner creativity }\end{array}$ \\
\hline & Class Podcast & stay & community building \\
\hline \multicolumn{2}{|c|}{$\begin{array}{l}\text { Assessment } \\
\text { (assignments/oral } \\
\text { presentations) } \\
\end{array}$} & $\begin{array}{l}\text { - } \quad \begin{array}{l}\text { stay, especially individual feedback } \\
\text { - } \\
\text { more learner-focused, real-life, } \\
\text { problem-solving tasks }\end{array} \\
\end{array}$ & $\begin{array}{ll}\text { - } & \text { personalised learning and } \\
\text { teaching } \\
\text { - } \quad \text { real-life problem solving } \\
\end{array}$ \\
\hline
\end{tabular}


This study is exploratory in nature. We acknowledge the limitations associated with it. First, students' perception and evaluation of the virtual classroom and the online learning community have not been formally sought. Second, most of the findings or assertions made by the author regarding how students learn in online setting are mere observations. Third, the list of the characteristics of the learner-centred approach drawn up and subsequently used to guide the re-design of the online papers by this author is by no means an exhaustive and thorough description of the approach. Further research will be required to establish a theoretically sound and practical framework for learn-centred pedagogy.

\section{References}

1. Barker, P. (2002). On Being an Online Tutor. Innovations in Education and Teaching International, 39(1), 3-13.

2. Bennett, S., \& Marsh, D. (2002). Are we expecting online tutors to run before they can walk? Innovations in Education and Teaching International, 39(1), 14-20.

3. Brown, J.S., \& Adler, R.P. (2008). Open education, the long tail, and learning 2.0. Educause Review, 43(1), 16-32.

4. Chambers, A. (2005). Integrating corpus consultation in language studies. Language Learning and Technology, 9(2), 111-125.

5. Compton, L. (2009). Preparing language teachers to teach language online: a look at skills, roles, and responsibilities. Computer Assisted Language Learning, 22(1), 73-99.

6. Coverdale-Jones, T. (2000). The use of video-conferencing as a communication tool for language learning: Issues and considerations. IALL Journal of Language Learning Technologies, 32(1), 27-40.

7. Davis, N., \& Rose, R. (2007). Professional developments for virtual schooling and online learning. $\quad$ Retrieved 27July 2010 from http://www.inacol.org/research/docs/NACOL_PDforVSandOlnLrng.pdf.

8. Guichon, N. (2009). Training future language teachers to develop online tutors' competence through reflective analysis. ReCall European Association for Computer Assisted Language Learning, 21(2), 166-185.

9. Hampel, R., \& Stickler, U. (2005). New skills for new classrooms: Training tutors to teach languages online. Computer Assisted Language Learning, 18(4), 311-326.

10. Harrison, R., \& Thomas, M. (2009). Identity in Online Communities: Social Networking Sites and Language Learning. International Journal of Emerging Technologies \& Society, 7(2), 109-124.

11. Jenks, C.J. (2009). When is it appropriate to talk? Managing overlapping talk in multi-participant voice-based chat room. Computer Assisted Language Learning. 22(1), 19-30.

12. Johnson, C., Corazzini, K., \& Shaw, R. (2011). Assessing the feasibility of using virtual environments in distance education. Knowledge Management \& ELearning : An International Journal, 3(1), 5-16.

13. Kabata, K., \& Wiebe, G. (2005). Challenge of developing and implementing multimedia courseware for a Japanese language program. CALICO Journal, 22(2), $237-250$ 
14. Lai, C., Zhao, Y., \& Li, N. (2008). Designing a distance foreign language learning environment. In S. Goertler \& P. Winke (Eds.), Opening doors through distance learning education: Principles, perspectives, and practices. CALICO Monograph Series (Vol. 7, pp. 85-108). Texas: Computer Assisted Language Instruction Consortium (CALICO).

15. McLoughlin, C., \& Lee, M.J.Y. (2010). Personalised and self regulated learning in the Web 2.0 era: International exemplars of innovative pedagogy using social software. Australasian Journal of Educational Technology, 26(1), 28-43.

16. Palmer, S., \& Holt, D. (2009) Staff and student perceptions of an online learning environment: Difference and development. Australasian Journal of Educational Technology, 25(3), 366-381.

17. Parker, M.A., \& Martin, F. (2010). Technology for Education (T4E), 2010 International Conference (978-4244-7362-5). IEEE Electronic Library Online, 93100 .

18. Stickler, U., \& Hauck, M. (2006a). What does it take to teach online? Towards a pedagogy for online language teaching and learning. CALICO Journal, 23(3), 463475.

19. Wang, Y. (2004). Supporting synchronous distance learning with desktop videoconferencing. Language Learning \& technology, 8(3), 90-121.

20. Wang, Y., \& Chen, N.-S. (2009). Criteria for evaluating synchronous learning management system: arguments from the distance language classroom. Computer Assisted Language Learning, 22(1), 1-18

21. White, C. (2003). Language learning in distance education. Cambridge: Cambridge University Press.

22. Wilson, G., \& Stacey, E. (2004). Online interaction impacts on learning: teaching the teachers to teach online. Australasian Journal of Educational Technology, 20(1), 33-48.

23. Winke, S., Goertler, S., \& Amuzie, G.L. (2010). Commonly taught and less commonly taught language learners: are they equally prepared for CALL and online language learning? Computer Assisted Language Learning, 23(3), 199-219. 